\title{
ESTUDO DA PRODUÇÃO DE LARANJA: DETECÇÃO DE CARACTERÍSTICAS REGIONAIS COM MODELOS DE SHIFT-SHARE E DERIVADA NA REGIÃO NORTE
}

\author{
Amanda Catarine Ribeiro Silva'; Gabriela Mourão de Almeida²; Whesley Thiago dos Santos Lobato ${ }^{3}$; Fabiola \\ Suany de Souza Almeida4; Antonio Alan Santos de Souza ${ }^{5}$; Deice Juane Ferreira Vidal6; Eliane do Socorro \\ Ferreira Lima ${ }^{7}$; Wanderson Cunha Pereira ${ }^{8}$.

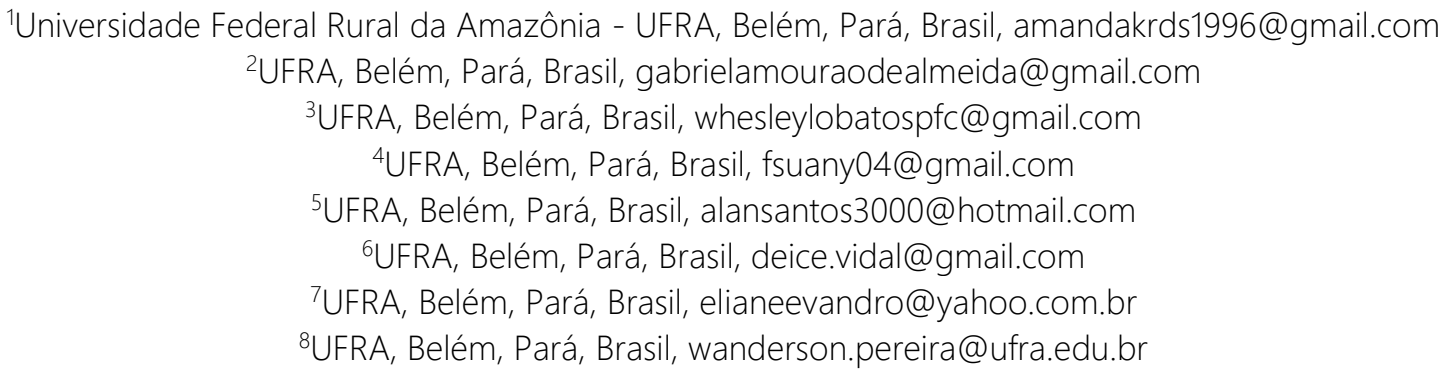

RESUMO: A laranja (Citrus sinensis (L.) Osbeck) é uma das principais culturas de interesse para o Brasil, pois este detém grande parte da produção mundial, a região Norte tem como maior produtor o estado do Pará que é responsável por $2 \%$ da produção nacional e o principal município responsável por essa produção é Capitão Poço. Com base nisto o estudo teve por objetivo avaliar o desenvolvimento de diferentes setores ligados a produção de laranja fazendo um comparativo com a produção nacional através da análise shift-share para avaliar o desenvolvimento nos anos de 1990-2014 e em seguida foi aplicado o modelo matemático derivada com o objetivo de analisar números não comparativos com o objetivo de embasar a análise. Após todo o processo podemos inferir a instabilidade na produção de laranja e que o baixo nível tecnológico influencia diretamente na produção, pois faz com que se ocupe mais áreas e não aumenta a produção.

PALAVRAS-CHAVE: Citrus sinensis, economia, produção.

\section{ORANGE PRODUCTION STUDY: DETECTION OF REGIONAL FEATURES WITH SHIFT -SHARE OF MODELS AND DERIVATIVE IN NORTHERN REGION}

\begin{abstract}
The Orange (Citrus sinensis (L.) Osbeck) is one of the main crops of interest for Brazil, since this one holds great part of the world production, the North region has as largest producer the state of Pará that is responsible for $2 \%$ of the national production and the main municipality responsible for this production is Capitão Poço. Based on this, the objective of this study was to evaluate the development of different sectors linked to orange production, comparing it with the national production through the shift-share analysis to evaluate the development in the years of 1990-2014 and then applied the mathematical model derived with the objective of analyzing non-comparative numbers in order to base the analysis. After all the process we can infer the instability in the production of orange and
\end{abstract}


that the low technological level directly influences the production, because it makes it occupy more areas and does not increase the production.

KEYWORDS: Citrus sinensis, economy, production.

\section{ESTUDIO DE LA PRODUCCIÓN DE NARANJA: DETECCIÓN DE CARACTERISTICAS REGIONALES CON MODELOS DE SHIFT-SHARE $Y$ DERIVADA EN LA REGIÓN NORTE}

RESUMEN: La naranja (Citrus sinensis (L.) Osbeck) es una de las principales culturas de interés para Brasil, pues este detiene gran parte de la producción mundial, la región Norte tiene como mayor productor el estado de Pará que es responsable del 2\% de la producción nacional y el principal municipio responsable de esa producción es el Capitán Pozo. Con base en esto el estudio tuvo por objetivo evaluar el desarrollo de diferentes sectores ligados a la producción de naranja haciendo un comparativo con la producción nacional a través del análisis shift-share para evaluar el desarrollo en los años 1990-2004 y luego fue aplicado el modelo matemático derivada con el objetivo de analizar números no comparativos con el objetivo de basar el análisis. Después de todo el proceso podemos inferir la inestabilidad en la producción de naranja y que el bajo nivel tecnológico influye directamente en la producción, pues hace que se ocupe más áreas y no aumente la producción.

PALABRAS CLAVE: Citrus sinensis, economia, produção.

\section{INTRODUÇÃO}

O Brasil tem se destacado ao longo dos anos por sua grande produção de citros e exportação de suco de laranja para diversos países. Essa fruta veio ao Brasil trazida pelas caravelas Portuguesas no século XVI, segundo Perez e Santos (2014), este fato teve influência no mercado produtivo tornando o Brasil um dos maiores produtores mundial de citros.

A laranja é considerada um eficaz antioxidante, e está relacionada com a prevenção de inúmeras doenças devido o seu alto índice de vitamina C (FIGUEIREDO, 2009). Destacando-se por ser um dos maiores exportadores de laranja do mundo, o Brasil, tem como principal propósito a exportação, e seu maior consumo é in natura.

De acordo com pesquisas da EMBRAPA (2013), a produção de laranja está distribuída nas regiões brasileiras da seguinte forma, a região sudeste detém o maior percentual quantitativo na 
produção por hectare, sendo equivalente a 79,71\%, a região nordeste é a segunda maior produtora com 9,61\%, a região sul é responsável por 8,12\%, o norte apresenta uma taxa de 1,69\%, e o centrooeste com 0,87\%, o que representa a menor produção regional no Brasil.

O estado do Pará não possui um grande percentual na taxa de produção da laranja a nível nacional, isso pelo fato de muitas cidades não obter as condições favoráveis com relação ao clima e a fitossanidade no desenvolvimento desta cultura. Porém há no estado alguns municípios, situados na microrregião do Guamá, que ao contrário de muitos no Pará, possui uma produção quantitativa e qualitativa no cultivo da laranja, sendo eles, o município de Capitão Poço, Irituia e Ourém (RIBEIRO; RIBEIRO, 2006).

O município de Capitão Poço está situado na microrregião do Guamá, caracterizado no setor agrícola, como um dos maiores produtores de laranja nesta região. Este desenvolvimento segundo Alves et al. (2015), é devido as condições edafoclimáticas, como clima e um solo favorável para crescimento da produção dos citros em Capitão Poço e nos municípios arredores.

O seguinte trabalho foi realizado através de avaliações feitas por dois métodos de modelagens matemáticas, o método shift-share e a derivada. A modelagem matemática visa relacionar conteúdos teóricos com práticas diárias, afim de que a compreensão seja maior. Segundo Almeida e Brito (2005), o ensino por Modelagem Matemática configura uma atividade que amplifica-se segundo um esquema denominado - ciclo de modelagem - onde a escolha da problemática tem a participação direta dos sujeitos envolvidos, desta forma, a modelagem é uma abordagem por meio da matemática de um problema não propriamente matemático. $\bigcirc$ método Shift-share é uma modelagem relacionada a dinâmica regional, interligando o crescimento econômico com a produtividade da região.

Zilli (2015), afirma que o modelo shift-share compreende uma análise estatística que pode ser utilizada em diversos campos de conhecimento. Essa análise realiza a decomposição das taxas de variação em fontes de conhecimento, ou seja, busca ilustrar - comportamento da produção agrícola mediante a decomposição dos fatores responsáveis pela variação da produção.

Outra forma de medir uma taxa de produção agrícola é através do método matemático, denominado derivada. Para Mantai e Tiecker (2011) através da utilização de derivadas pode-se 
caracterizar e minimizar os erros ocorridos no campo, desta forma, os dados do levantamento tornam-se mais exatos e mais confiáveis.

Este trabalho teve por objetivo avaliar o desenvolvimento da produção de laranja na região Norte, no estado do Pará e no município de Capitão Poço em relação ao desenvolvimento nacional através da análise Shift-Share, para que houvesse um complemento da análise foi realizado um método matemático chamado derivada com o objetivo de retirar valores concretos da análise para a elaboração de gráficos que demonstre o percentual de desenvolvimento da atividade.

\section{MATERIAL E MÉTODOS}

Os dados básicos foram adquiridos no site do IBGE (Instituto Brasileiro de Geografia e Estatística), esses dados referentes a Área destinada a colheita em Hectares, Área colhida em Hectares, quantidade Produzida em Toneladas e o Valor da produção em Reais. Todos alusivos ao Brasil, a região Norte, ao estado do Pará e ao município de Capitão Poço sendo este o maior produtor de laranja do estado, todos referentes aos últimos vinte e quatro anos, de 1990-2014. Os dados foram agrupados de três em três anos para que houvesse uma maior consistência, ou seja, se a possível mudança não foi apenas devido a algum imprevisto anual e sim a uma condição de estrutura econômica.

\section{Modelo Shift-Share}

Fizemos o uso desta análise para retratar o desenvolvimento da Área destinada a colheita (Hectares), Área colhida (Hectares), Produção (Toneladas) e Valor da Produção (Reais) nos últimos vinte e quatro anos no município de Capitão Poço, no estado do Pará e na região Norte com o objetivo de fazer um comparativo com 0 Brasil. A análise econômica shift-share foi proposta por Dunn (1960) e no presente trabalho o modelo adotado foi o clássico sendo formada por três efeitos: $O$ efeito nacional, efeito proporcional, efeito regional e a somatória de todos o efeito totais.

O efeito nacional nada mais é que a produção hipotética, ou seja, a variação que a produção deveria ter na região caso 
ela variasse exatamente a mesma taxa que a produção nacional. $O$ efeito proporcional é a variação da produção regional em função da variação do tecido produtivo nacional, quanto maior a quantidades de anos com elevado crescimento produtivo, maior o efeito proporcional da região. $O$ efeito regional é a variação da produção que não pode ser explicada pelos outros dois efeitos, pois depende de fatores locais como, por exemplo, o clima. O efeito total é a somatória de todos os efeitos anteriores para gerar a variação líquida da produção.

Tabela 1. Tabela das somatórias dos efeitos.

\begin{tabular}{c}
\hline cijt $=$ Eijt - Eijt-10 $=$ nijt + mijt + rijt \\
nijt $=$ Eijt-10* $\mathrm{g}$ \\
mijt $=$ Eijt-10 * (gi $-\mathrm{g})$ \\
rijt $=$ Eijt-10 * (gij - gi $)$ \\
mjt $=$ mi ij $\sum /$ Ei ijt $\sum 10$ \\
rjt $=$ ri ij $\sum /$ Ei ijt $\sum 10$ \\
sjt $=$ mjt + rjt
\end{tabular}

Legenda:

*Eijt é a produção i, na região j, no ano t.

*cijt é a variação total da produção durante os três anos

*g é a taxa de produção nacional.

* gi é a taxa de crescimento da produção no setor i, ao nível nacional.

*gij é a taxa de crescimento da produção i, na região j.

*sjit constitui o shift total da região comparativamente ao conjunto do país.

Para auxiliar a análise shift-share foi aplicado o método matemático da derivada para poder obter valores concretos das variáveis sem que essas estivessem sendo influenciadas ou comparadas com as variáveis nacionais como na análise acima, através desse método foi obtido gráficos mostrando o desenvolvimento de cada setor em função dos anos que permaneceram agrupados de três em três (Tabela 2). 
Tabela 2. Tabela demonstrando o progresso de cada seção alinhados de três em três.

\begin{tabular}{ll}
\hline B (ano inicial) & B( ano inicial +3$)$-B(ano inicial)/3 \\
\hline B (ano inicial) & $\begin{array}{l}\text { É o ano que se tem interesse, o modelo acima é } \\
\text { aplicável quando se faz o comparativo com anos } \\
\text { maiores que o de interesse. }\end{array}$ \\
B (ano inicial) & B(ano inicial -3$)$-B(ano inicial $) /-3$ \\
\hline
\end{tabular}

Modelo aplicável quando o ano de interesse e maior do que o comparado. Todas as analisem foram preparadas usando o programa Microsoft Excel 2010 bem como os gráficos do presente trabalho.

\section{RESULTADOS E DISCUSSÃO}

Nos resultados gerados pela análise shift-share, é possível observar os mais diversos aspectos em relação à região como, por exemplo: a região Norte em 1990/1993 (Tabela 3) apresentou uma taxa de crescimento de área destinada a colheita e colhida maior que a nacional, porém a sua produção foi inferior. Para
Silva et al., (2011a) o fato da região norte apresentar grande áreas passíveis ao cultivo, e não sofre com o ataque de algumas pragas e doenças que prejudicam a produção de citros em outros estados, facilitou a expansão das áreas destinadas à produção.

Podemos inferir que a região devido à baixa tecnologia estava ocupando muita área e produzindo pouco, outra situação que podemos deduzir foi que o estado do Pará e o Município de Capitão Poço detém uma grande parte da produção, pois suas variações foram superiores a nacional assim mostrando o dinamismo de ambos. 
Tabela 3 - Produtividade da região Norte, Pará e Capitão Poço entre 1990-93.

\begin{tabular}{|c|c|c|c|c|c|c|c|c|}
\hline $\begin{array}{l}\text { 1990/1993 } \\
\text { Norte }\end{array}$ & $\begin{array}{c}\text { Efeito } \\
\text { Nacional }\end{array}$ & $\%$ & $\begin{array}{c}\text { Efeito } \\
\text { Proporcional } \\
\end{array}$ & $\%$ & $\begin{array}{c}\text { Efeito } \\
\text { Regional }\end{array}$ & $\%$ & $\begin{array}{l}\text { Efeito } \\
\text { total }\end{array}$ & $\%$ \\
\hline $\begin{array}{l}\text { Área destinada à } \\
\text { colheita (Hectares) }\end{array}$ & 616,57 & $1,1 \%$ & $-1705,23$ & $\begin{array}{c}- \\
231,5 \%\end{array}$ & 8000,65 & $1,8 \%$ & 6912,00 & $1,4 \%$ \\
\hline $\begin{array}{l}\text { Área colhida } \\
\text { (Hectares) }\end{array}$ & 612,55 & $1,1 \%$ & $-1701,74$ & $\begin{array}{c}- \\
231,0 \%\end{array}$ & 7968,18 & $1,8 \%$ & 6879,00 & $1,4 \%$ \\
\hline $\begin{array}{l}\text { Quantidade } \\
\text { produzida } \\
\text { (Toneladas) }\end{array}$ & 56270,40 & $97,7 \%$ & 2901,88 & $393,9 \%$ & 417540,72 & $96,4 \%$ & 476713,00 & $97,0 \%$ \\
\hline Valor da produção & 92,23 & $0,2 \%$ & 1241,72 & $168,6 \%$ & $-1276,95$ & $-0,3 \%$ & 57,00 & $0,0 \%$ \\
\hline Total & 57591,76 & $100 \%$ & 736,64 & $100,0 \%$ & 432969,24 & $100,0 \%$ & 491297,64 & $100,0 \%$ \\
\hline $\begin{array}{ll}\text { 1990/1993 Brasil/ } \\
\text { Para }\end{array}$ & $\begin{array}{c}\text { Efeito } \\
\text { Nacional }\end{array}$ & $\%$ & $\begin{array}{c}\text { Efeito } \\
\text { Proporcional } \\
\end{array}$ & $\%$ & $\begin{array}{c}\text { Efeito } \\
\text { Regional } \\
\end{array}$ & $\%$ & $\begin{array}{l}\text { Efeito } \\
\text { total } \\
\end{array}$ & $\%$ \\
\hline $\begin{array}{l}\text { Área destinada à } \\
\text { colheita (Hectares) }\end{array}$ & 382,43 & $1 \%$ & $-1057,67$ & $-137 \%$ & 7296,24 & $2 \%$ & 6621,00 & $1 \%$ \\
\hline $\begin{array}{l}\text { Área colhida } \\
\text { (Hectares) }\end{array}$ & 381,04 & $1 \%$ & $-1058,58$ & $-137 \%$ & 7249,54 & $2 \%$ & 6572,00 & $1 \%$ \\
\hline $\begin{array}{l}\text { Quantidade } \\
\text { produzida } \\
\text { (Toneladas) }\end{array}$ & 41526,90 & $98 \%$ & 2141,55 & $278 \%$ & 444895,55 & $97 \%$ & 488564,00 & $97 \%$ \\
\hline Valor da produção & 55,43 & $0 \%$ & 746,34 & $97 \%$ & $-468,77$ & $0 \%$ & 333,00 & $0 \%$ \\
\hline Total & 42345,81 & $100 \%$ & 771,64 & $100 \%$ & 459744,19 & $100 \%$ & 502861,64 & $100 \%$ \\
\hline $\begin{array}{l}\text { 1990/1993 Brasil/ } \\
\text { Capitão Poço }\end{array}$ & $\begin{array}{c}\text { Efeito } \\
\text { Nacional } \\
\end{array}$ & $\%$ & $\begin{array}{c}\text { Efeito } \\
\text { Proporcional } \\
\end{array}$ & $\%$ & $\begin{array}{c}\text { Efeito } \\
\text { Regional } \\
\end{array}$ & $\%$ & $\begin{array}{l}\text { Efeito } \\
\text { total } \\
\end{array}$ & $\%$ \\
\hline $\begin{array}{l}\text { Área destinada à } \\
\text { colheita (Hectares) }\end{array}$ & 210,65 & $1 \%$ & $-582,59$ & $-1484 \%$ & 5731,94 & $1 \%$ & 5360,00 & $1 \%$ \\
\hline $\begin{array}{l}\text { Área colhida } \\
\text { (Hectares) }\end{array}$ & 210,65 & $1 \%$ & $-585,21$ & $-1491 \%$ & 5734,56 & $1 \%$ & 5360,00 & $1 \%$ \\
\hline $\begin{array}{l}\text { Quantidade } \\
\text { produzida } \\
\text { (Toneladas) }\end{array}$ & 19552,75 & $98 \%$ & 1008,34 & $2569 \%$ & 371995,91 & $97 \%$ & 392557,00 & $97 \%$ \\
\hline Valor da produção & 14,76 & $0 \%$ & 198,71 & $506 \%$ & $-34,47$ & $0 \%$ & 179,00 & $0 \%$ \\
\hline Total & 19988,82 & $100 \%$ & 39,25 & $100 \%$ & 383467,18 & $100 \%$ & 403495,25 & $100 \%$ \\
\hline
\end{tabular}

Nos anos de 1993/1996 (Tabela 4) quando comparados com os anos anteriores todas as variáveis tiveram quedas nas suas taxas menos o valor da produção que obteve um aumento significativo, que pode ser associado a mudança da moeda Brasileira e consequentemente a valorização da mesma. Para Amaro (1997) com o advento do Plano Real e seu sucesso na redução das taxas de inflação e de juros, o mercado interno brasileiro torna-se capaz de absorver quantidades significativas da fruta. uma vez que a laranja é uma das frutas de maior aceitação entre os consumidores de todo o País. 
Tabela 4. Produtividade da região Norte, Pará e Capitão Poço entre 1993-96.

\begin{tabular}{|c|c|c|c|c|c|c|c|c|}
\hline Brasil/ Norte & $\begin{array}{c}\text { Efeito } \\
\text { Nacional } \\
\end{array}$ & $\%$ & $\begin{array}{c}\text { Efeito } \\
\text { Proporcional } \\
\end{array}$ & $\%$ & $\begin{array}{c}\text { Efeito } \\
\text { Regional } \\
\end{array}$ & $\%$ & Efeito total & $\%$ \\
\hline $\begin{array}{l}\text { Área destinada à colheita } \\
\text { (Hectares) }\end{array}$ & 2112,33 & $1,2 \%$ & 1127,61 & $27,0 \%$ & 2192,07 & $0,7 \%$ & 5432,00 & $1,1 \%$ \\
\hline Área colhida (Hectares) & 2100,17 & $1,2 \%$ & 1117,60 & $26,8 \%$ & 1877,23 & $0,6 \%$ & 5095,00 & $1,0 \%$ \\
\hline $\begin{array}{l}\text { Quantidade produzida } \\
\text { (Toneladas) }\end{array}$ & 172188,96 & $97,5 \%$ & $-15740,59$ & $\begin{array}{c}- \\
377,3 \%\end{array}$ & 288844,63 & $86,3 \%$ & 445293,00 & $86,4 \%$ \\
\hline Valor da produção & 185,45 & $0,1 \%$ & 17666,84 & $423,5 \%$ & 37768,71 & $11,3 \%$ & 55621,00 & $10,8 \%$ \\
\hline Total & 176586,90 & $100,0 \%$ & 4171,46 & $100,0 \%$ & 334854,10 & $100,0 \%$ & 515612,46 & $100,0 \%$ \\
\hline Brasil/ Para & $\begin{array}{c}\text { Efeito } \\
\text { Nacional }\end{array}$ & $\%$ & $\begin{array}{c}\text { Efeito } \\
\text { Proporcional } \\
\end{array}$ & $\%$ & $\begin{array}{c}\text { Efeito } \\
\text { Regional }\end{array}$ & $\%$ & Efeito total & $\%$ \\
\hline $\begin{array}{l}\text { Área destinada à colheita } \\
\text { (Hectares) }\end{array}$ & 1621,99 & $1 \%$ & 865,85 & $30 \%$ & 817,16 & $0 \%$ & 3305,00 & $1 \%$ \\
\hline Área colhida (Hectares) & 1612,77 & $1 \%$ & 858,23 & $30 \%$ & 814,00 & $0 \%$ & 3285,00 & $1 \%$ \\
\hline $\begin{array}{l}\text { Quantidade produzida } \\
\text { (Toneladas) }\end{array}$ & 145344,91 & $98 \%$ & $-13286,65$ & $-465 \%$ & 333852,74 & $91 \%$ & 465911,00 & $90 \%$ \\
\hline Valor da produção & 151,38 & $0 \%$ & 14421,13 & $504 \%$ & 29551,49 & $8 \%$ & 44124,00 & $8 \%$ \\
\hline Total & 148731,04 & $100 \%$ & 2858,57 & $100 \%$ & 367893,96 & $100 \%$ & 519483,57 & $100 \%$ \\
\hline $\begin{array}{l}\text { 1993/1996 Brasil/ } \\
\text { Capitão Poço }\end{array}$ & $\begin{array}{c}\text { Efeito } \\
\text { Nacional } \\
\end{array}$ & $\%$ & $\begin{array}{c}\text { Efeito } \\
\text { Proporcional } \\
\end{array}$ & $\%$ & $\begin{array}{c}\text { Efeito } \\
\text { Regional } \\
\end{array}$ & $\%$ & Efeito total & $\%$ \\
\hline $\begin{array}{l}\text { Área destinada à colheita } \\
\text { (Hectares) }\end{array}$ & 1122,30 & $1 \%$ & 599,11 & $-29 \%$ & $-1271,41$ & $-1 \%$ & 450,00 & $0 \%$ \\
\hline Área colhida (Hectares) & 1122,30 & $1 \%$ & 597,23 & $-29 \%$ & $-1269,53$ & $-1 \%$ & 450,00 & $0 \%$ \\
\hline $\begin{array}{l}\text { Quantidade produzida } \\
\text { (Toneladas) }\end{array}$ & 90148,65 & $98 \%$ & $-8240,91$ & $401 \%$ & 150124,25 & $96 \%$ & 232032,00 & $94 \%$ \\
\hline Valor da produção & 52,37 & $0 \%$ & 4989,48 & $-243 \%$ & 10888,14 & $7 \%$ & 15930,00 & $6 \%$ \\
\hline Total & 92445,62 & $100 \%$ & $-2055,08$ & $100 \%$ & 156416,38 & $100 \%$ & 246806,92 & $100 \%$ \\
\hline
\end{tabular}

Nos anos de 1996/1999 (Tabela 5) em todos os setores o efeito regional obteve quedas bruscas, este evento pode estar associado ao baixo retorno financeiro da cultura devido a competição com a produção estadunidense, a nível regional, estadual e municipal, pois nacionalmente a cultura teve um crescimento bastante significativo. Este crescimento a nível nacional se deu, segundo Barros et al. (2016) devido ao aumento da produção destinada ao consumo de mesa o que trouxe uma estabilidade na produção total de laranjas no mercado brasileiro. 
Tabela 5. Produtividade da região Norte, Pará e Capitão Poço entre 1996-99.

\begin{tabular}{|c|c|c|c|c|c|c|c|c|}
\hline $\begin{array}{l}\text { 1996/1999 } \\
\text { Brasil/ Norte }\end{array}$ & $\begin{array}{c}\text { Efeito } \\
\text { Nacional }\end{array}$ & $\%$ & $\begin{array}{c}\text { Efeito } \\
\text { Proporcional }\end{array}$ & $\%$ & $\begin{array}{c}\text { Efeito } \\
\text { Regional }\end{array}$ & $\%$ & Efeito total & $\%$ \\
\hline \multicolumn{9}{|l|}{ Área } \\
\hline $\begin{array}{l}\text { destinada à } \\
\text { colheita } \\
\text { (Hectares) }\end{array}$ & 1873,34 & $1,2 \%$ & $-479,58$ & $-5,4 \%$ & $-2625,75$ & $0,9 \%$ & $-1232,00$ & $1,1 \%$ \\
\hline $\begin{array}{l}\text { Área colhida } \\
\text { (Hectares) }\end{array}$ & 1835,59 & $1,1 \%$ & $-482,21$ & $-5,4 \%$ & $-2357,38$ & $0,8 \%$ & $-1004,00$ & $0,9 \%$ \\
\hline $\begin{array}{l}\text { Quantidade } \\
\text { produzida } \\
\text { (Toneladas) }\end{array}$ & 152927,54 & $94,6 \%$ & $-3676,92$ & $-41,3 \%$ & $-258250,61$ & $92,9 \%$ & $-109000,00$ & $101,4 \%$ \\
\hline $\begin{array}{l}\text { Valor da } \\
\text { produção }\end{array}$ & 5027,64 & $3,1 \%$ & 13552,29 & $152,0 \%$ & $-23725,92$ & $8,5 \%$ & $-5146,00$ & $4,8 \%$ \\
\hline Total & 161664,10 & $100,0 \%$ & 8913,57 & $100,0 \%$ & $-278046,10$ & $100,0 \%$ & $-107468,43$ & $100,0 \%$ \\
\hline $\begin{array}{l}\text { 1996/1999 } \\
\text { Brasil/ Para }\end{array}$ & $\begin{array}{c}\text { Efeito } \\
\text { Nacional } \\
\end{array}$ & $\%$ & $\begin{array}{c}\text { Efeito } \\
\text { Proporcional } \\
\end{array}$ & $\%$ & $\begin{array}{c}\text { Efeito } \\
\text { Regional } \\
\end{array}$ & $\%$ & Efeito total & $\%$ \\
\hline \multicolumn{9}{|l|}{ Área } \\
\hline $\begin{array}{l}\text { destinada à } \\
\text { colheita } \\
\text { (Hectares) }\end{array}$ & 1362,10 & $1 \%$ & $-348,70$ & $-5 \%$ & $-1755,40$ & $1 \%$ & $-742,00$ & $0 \%$ \\
\hline $\begin{array}{l}\text { Área colhida } \\
\text { (Hectares) }\end{array}$ & 1354,25 & $1 \%$ & $-355,76$ & $-5 \%$ & $-1683,49$ & $1 \%$ & $-685,00$ & $0 \%$ \\
\hline $\begin{array}{l}\text { Quantidade } \\
\text { produzida } \\
\text { (Toneladas) }\end{array}$ & 137026,84 & $95 \%$ & $-3294,62$ & $-49 \%$ & $-302505,23$ & $94 \%$ & $-168773,00$ & $99 \%$ \\
\hline $\begin{array}{l}\text { Valor da } \\
\text { produção }\end{array}$ & 3991,22 & $3 \%$ & 10758,58 & $159 \%$ & $-21758,80$ & $7 \%$ & $-7009,00$ & $4 \%$ \\
\hline Total & 143734,41 & $100 \%$ & 6759,50 & $100 \%$ & $-320943,41$ & $100 \%$ & $-170449,50$ & $100 \%$ \\
\hline $\begin{array}{l}\text { 1996/1999 } \\
\text { Brasil/ Capitão } \\
\text { Poço }\end{array}$ & $\begin{array}{l}\text { Efeito } \\
\text { Nacional }\end{array}$ & $\%$ & $\begin{array}{c}\text { Efeito } \\
\text { Proporcional }\end{array}$ & $\%$ & $\begin{array}{c}\text { Efeito } \\
\text { Regional }\end{array}$ & $\%$ & Efeito total & $\%$ \\
\hline \multicolumn{9}{|l|}{ Área } \\
\hline $\begin{array}{l}\text { destinada à } \\
\text { colheita } \\
\text { (Hectares) }\end{array}$ & 780,48 & $1 \%$ & $-199,81$ & $-13 \%$ & $-2266,68$ & $1 \%$ & $-1686,00$ & $1 \%$ \\
\hline $\begin{array}{l}\text { Área colhida } \\
\text { (Hectares) }\end{array}$ & 780,48 & $1 \%$ & $-205,03$ & $-13 \%$ & $-2261,45$ & $1 \%$ & $-1686,00$ & $1 \%$ \\
\hline $\begin{array}{l}\text { Quantidade } \\
\text { produzida } \\
\text { (Toneladas) }\end{array}$ & 79967,52 & $96 \%$ & $-1922,71$ & $-124 \%$ & $-250790,82$ & $97 \%$ & $-172746,00$ & $99 \%$ \\
\hline $\begin{array}{l}\text { Valor da } \\
\text { produção }\end{array}$ & 1439,44 & $2 \%$ & 3880,10 & $250 \%$ & $-4759,54$ & $2 \%$ & 560,00 & $0 \%$ \\
\hline Total & 82967,93 & $100 \%$ & 1552,55 & $100 \%$ & $-258525,93$ & $100 \%$ & $-174005,45$ & $100 \%$ \\
\hline
\end{tabular}

Dois setores se destacaram no ano de 1999/2002 (Tabela 6) a área destinada a colheita e a área colhida, essas obtiveram um aumento significativo, isso pode ser associado a necessidade de aumentar a produção logo optaram pela expansão devido ao baixo investimento na região e a alta disponibilidade de área. Silva et al., (2011) destaca o fato do estado ter grandes áreas cultiváveis, permitindo ao estado alcançar índices elevados de crescimento da citricultura. 
Tabela 6. Produtividade da região Norte, Pará e Capitão Poço entre 1999-02.

\begin{tabular}{|c|c|c|c|c|c|c|c|c|}
\hline $\begin{array}{l}\text { 1999/2002 } \\
\text { Brasil/ Norte }\end{array}$ & $\begin{array}{l}\text { Efeito } \\
\text { Nacional }\end{array}$ & $\%$ & $\begin{array}{c}\text { Efeito } \\
\text { Proporcional }\end{array}$ & $\%$ & $\begin{array}{c}\text { Efeito } \\
\text { Regional }\end{array}$ & $\%$ & Efeito total & $\%$ \\
\hline $\begin{array}{l}\text { Área destinada à } \\
\text { colheita (Hectares) }\end{array}$ & $-15931,12$ & $1,2 \%$ & 12068,85 & $15,2 \%$ & 1978,27 & $-7,4 \%$ & $-1884,00$ & $0,1 \%$ \\
\hline $\begin{array}{l}\text { Área colhida } \\
\text { (Hectares) }\end{array}$ & $-15771,89$ & $1,2 \%$ & 11948,37 & $15,0 \%$ & 1996,52 & $-7,5 \%$ & $-1827,00$ & $0,1 \%$ \\
\hline $\begin{array}{l}\text { Quantidade } \\
\text { produzida } \\
\text { (Toneladas) }\end{array}$ & $-1293808,53$ & $94,7 \%$ & $-68180,51$ & $-85,7 \%$ & $-15799,97$ & $59,4 \%$ & $-1377789,00$ & $104,9 \%$ \\
\hline Valor da produção & $-41291,14$ & $3,0 \%$ & 123748,12 & $155,5 \%$ & $-94339,98$ & $354,9 \%$ & $-11883,00$ & $0,9 \%$ \\
\hline Total & $-1366802,68$ & $100,0 \%$ & 79584,84 & $100,0 \%$ & $-26580,32$ & $100,0 \%$ & $-1313798,16$ & $100,0 \%$ \\
\hline $\begin{array}{l}\text { 1999/2002 } \\
\text { Brasil/ Para }\end{array}$ & $\begin{array}{l}\text { Efeito } \\
\text { Nacional } \\
\end{array}$ & $\%$ & $\begin{array}{c}\text { Efeito } \\
\text { Proporcional } \\
\end{array}$ & $\%$ & $\begin{array}{c}\text { Efeito } \\
\text { Regional }\end{array}$ & $\%$ & Efeito total & $\%$ \\
\hline $\begin{array}{l}\text { Área destinada à } \\
\text { colheita (Hectares) }\end{array}$ & $-11705,91$ & $1 \%$ & 8867,98 & $17 \%$ & 922,93 & $-4 \%$ & $-1915,00$ & $0 \%$ \\
\hline $\begin{array}{l}\text { Área colhida } \\
\text { (Hectares) }\end{array}$ & $-11680,43$ & $1 \%$ & 8848,79 & $17 \%$ & 948,64 & $-4 \%$ & $-1883,00$ & $0 \%$ \\
\hline $\begin{array}{l}\text { Quantidade } \\
\text { produzida } \\
\text { (Toneladas) }\end{array}$ & $-1102672,49$ & $95 \%$ & $-58108,11$ & $-114 \%$ & $-13575,41$ & $52 \%$ & $-1174356,00$ & $104 \%$ \\
\hline Valor da produção & $-30451,45$ & $3 \%$ & 91261,94 & $179 \%$ & $-65392,49$ & $249 \%$ & $-4582,00$ & $0 \%$ \\
\hline Total & $-1156510,28$ & $100 \%$ & 50870,61 & $100 \%$ & $-26225,72$ & $100 \%$ & $-1131865,39$ & $100 \%$ \\
\hline $\begin{array}{l}\text { 1999/2002 } \\
\text { Brasil/ } \\
\text { Capitão Poço }\end{array}$ & $\begin{array}{l}\text { Efeito } \\
\text { Nacional }\end{array}$ & $\%$ & $\begin{array}{c}\text { Efeito } \\
\text { Proporcional }\end{array}$ & $\%$ & $\begin{array}{l}\text { Efeito } \\
\text { Regional }\end{array}$ & $\%$ & Efeito total & $\%$ \\
\hline $\begin{array}{l}\text { Área destinada à } \\
\text { colheita (Hectares) }\end{array}$ & $-5703,68$ & $1 \%$ & 4320,90 & $24 \%$ & 1099,77 & $-10 \%$ & $-283,00$ & $0 \%$ \\
\hline $\begin{array}{l}\text { Área colhida } \\
\text { (Hectares) } \\
\text { Quantidade }\end{array}$ & $-5703,68$ & $1 \%$ & 4320,96 & $24 \%$ & 1099,72 & $-10 \%$ & $-283,00$ & $0 \%$ \\
\hline $\begin{array}{l}\text { produzida } \\
\text { (Toneladas) }\end{array}$ & $-584392,72$ & $96 \%$ & $-30796,05$ & $-170 \%$ & $-1761,23$ & $16 \%$ & $-616950,00$ & $102 \%$ \\
\hline Valor da produção & $-13440,74$ & $2 \%$ & 40281,43 & $222 \%$ & $-29674,69$ & $267 \%$ & $-2834,00$ & $0 \%$ \\
\hline Total & $-609240,82$ & $100 \%$ & 18127,24 & $100 \%$ & $-11109,18$ & $100 \%$ & $-602222,76$ & $100 \%$ \\
\hline
\end{tabular}

Nos anos de 2002/2005 (Tabela 7) a região voltou a ter um aumento significativo no efeito nacional pode-se observar que a região o estado e o município são independentes do desenvolvimento nacional, pois cresceram ao invés de cair com este e a partir disto pode-se deduzir a presença de um mercado alternativo para a venda.
Dados semelhantes foram obtidos por Alves et al. (2015) onde em seu estudo ele afirma que a área colhida de 2000 a 2005 aumentou 2.362 ha- $^{1}$ e se manteve nos anos posteriores, o mesmo autor também descreve que após o ano de 2004 a área colhida, produção e produtividade apresentaram os valores de 8.610 ha- ${ }^{1}$, 146.370 toneladas e $17.000 \mathrm{~kg} \mathrm{ha-}{ }^{1}$, respectivamente. 
Tabela 7. Produtividade da região Norte, Pará e Capitão Poço entre 2002-05.

\begin{tabular}{|c|c|c|c|c|c|c|c|c|}
\hline $\begin{array}{l}2002 / 2005 \\
\text { Brasil/ Norte }\end{array}$ & $\begin{array}{c}\text { Efeito } \\
\text { Nacional }\end{array}$ & $\%$ & $\begin{array}{c}\text { Efeito } \\
\text { Proporcional }\end{array}$ & $\%$ & $\begin{array}{c}\text { Efeito } \\
\text { Regional }\end{array}$ & $\%$ & Efeito total & $\%$ \\
\hline $\begin{array}{l}\text { Área destinada à } \\
\text { colheita (Hectares) }\end{array}$ & $-431,97$ & $5,6 \%$ & $-107,17$ & $13,4 \%$ & 1107,14 & $6,3 \%$ & 568,00 & $6,3 \%$ \\
\hline $\begin{array}{l}\text { Área colhida } \\
\text { (Hectares) }\end{array}$ & $-428,56$ & $5,6 \%$ & $-74,32$ & $9,3 \%$ & 829,88 & $4,7 \%$ & 327,00 & $3,6 \%$ \\
\hline $\begin{array}{l}\text { Quantidade } \\
\text { produzida } \\
\text { (Toneladas) }\end{array}$ & $-5892,91$ & $76,5 \%$ & $-3142,97$ & $391,6 \%$ & 9872,89 & $56,3 \%$ & 837,00 & $9,3 \%$ \\
\hline Valor da produção & $-952,78$ & $12,4 \%$ & 2521,85 & $-314,2 \%$ & 6529,93 & $37,2 \%$ & 8099,00 & $89,7 \%$ \\
\hline Total & $-7706,21$ & $100,0 \%$ & $-802,62$ & $100,0 \%$ & 17537,21 & $100,0 \%$ & 9028,38 & $100,0 \%$ \\
\hline $\begin{array}{l}\text { 2002/2005 } \\
\text { Brasil/ Para }\end{array}$ & $\begin{array}{c}\text { Efeito } \\
\text { Nacional }\end{array}$ & $\%$ & $\begin{array}{c}\text { Efeito } \\
\text { Proporcional }\end{array}$ & $\%$ & $\begin{array}{c}\text { Efeito } \\
\text { Regional }\end{array}$ & $\%$ & Efeito total & $\%$ \\
\hline $\begin{array}{l}\text { Área destinada à } \\
\text { colheita (Hectares) }\end{array}$ & $-304,75$ & $5 \%$ & $-75,61$ & $11 \%$ & 685,37 & $5 \%$ & 305,00 & $4 \%$ \\
\hline $\begin{array}{l}\text { Área colhida } \\
\text { (Hectares) }\end{array}$ & $-304,75$ & $5 \%$ & $-52,85$ & $8 \%$ & 662,61 & $5 \%$ & 305,00 & $4 \%$ \\
\hline $\begin{array}{l}\text { Quantidade } \\
\text { produzida } \\
\text { (Toneladas) }\end{array}$ & $-5019,73$ & $78 \%$ & $-2677,27$ & $392 \%$ & 11033,00 & $77 \%$ & 3336,00 & $46 \%$ \\
\hline Valor da produção & $-802,30$ & $12 \%$ & 2123,57 & $-311 \%$ & 2679,73 & $19 \%$ & 4001,00 & $55 \%$ \\
\hline Total & $-6431,55$ & $100 \%$ & $-682,16$ & $100 \%$ & 14378,55 & $100 \%$ & 7264,84 & $100 \%$ \\
\hline $\begin{array}{l}\text { 2002/2005 } \\
\text { Brasil/ } \\
\text { Capitão Poço }\end{array}$ & $\begin{array}{c}\text { Efeito } \\
\text { Nacional }\end{array}$ & $\%$ & $\begin{array}{c}\text { Efeito } \\
\text { Proporcional }\end{array}$ & $\%$ & $\begin{array}{c}\text { Efeito } \\
\text { Regional }\end{array}$ & $\%$ & Efeito total & $\%$ \\
\hline $\begin{array}{l}\text { Área destinada à } \\
\text { colheita (Hectares) }\end{array}$ & $-163,98$ & $5 \%$ & $-40,69$ & $6 \%$ & 1933,67 & $4 \%$ & 1729,00 & $4 \%$ \\
\hline $\begin{array}{l}\text { Área colhida } \\
\text { (Hectares) }\end{array}$ & $-163,98$ & $5 \%$ & $-28,44$ & $4 \%$ & 1921,42 & $4 \%$ & 1729,00 & $4 \%$ \\
\hline $\begin{array}{l}\text { Quantidade } \\
\text { produzida } \\
\text { (Toneladas) }\end{array}$ & $-2789,84$ & $81 \%$ & $-1487,95$ & $222 \%$ & 33581,79 & $74 \%$ & 29304,00 & $71 \%$ \\
\hline Valor da produção & $-334,78$ & $10 \%$ & 886,12 & $-132 \%$ & 8819,67 & $19 \%$ & 9371,00 & $23 \%$ \\
\hline Total & $-3452,59$ & $100 \%$ & $-670,96$ & $100 \%$ & 45585,59 & $100 \%$ & 41462,04 & $100 \%$ \\
\hline
\end{tabular}

Em 2005/2008 (Tabela 8) novamente houve uma inversão enquanto os setores nacionais voltavam a crescer todos os setores na região, estado e município voltaram a cair consideravelmente. O acréscimo no setor nacional está diretamente ligado ao rápido recuo nos estoques do produto neste período, devido uma sequência de furacões que atingiram o estado da Flórida. Segundo
Oliveira et al. (2006) as regiões mais produtivas no mercado mundial de laranja são os estados da Flórida e São Paulo. Devido aos intemperes que o estado da Flórida sofreu com a ação de furacões, tendo sua produção significativamente afetada o mercado nacional teve alta na produtividade.

Já o decréscimo de produtividade regional pode estar ligado ao baixo nível 
tecnológico da maioria dos produtores de

Capitão poço, falta de assistência técnica, manejo inadequado como adubação insuficiente ou em excesso e em épocas inadequadas, como foi relatado por Alves et al. (2015). Tendo em vista que o município de capitão poço é responsável pela maior produtividade de citros do estado.

Tabela 8. Produtividade da região Norte, Pará e Capitão Poço entre 2005-08.

\begin{tabular}{|c|c|c|c|c|c|c|c|c|}
\hline $\begin{array}{rr}2005 / 2008 & \text { Brasil/ } \\
\text { Norte } & \\
\end{array}$ & $\begin{array}{c}\text { Efeito } \\
\text { Nacional }\end{array}$ & $\%$ & $\begin{array}{c}\text { Efeito } \\
\text { Proporcional } \\
\end{array}$ & $\%$ & $\begin{array}{c}\text { Efeito } \\
\text { Regional } \\
\end{array}$ & $\%$ & $\begin{array}{c}\text { Efeito } \\
\text { total }\end{array}$ & $\%$ \\
\hline $\begin{array}{l}\text { Área destinada à } \\
\text { colheita (Hectares) }\end{array}$ & 1455,51 & $5,6 \%$ & $-743,93$ & $36,0 \%$ & $-1009,58$ & $4,7 \%$ & $-298,00$ & $-11,4 \%$ \\
\hline Área colhida (Hectares) & 1425,61 & $5,5 \%$ & $-722,52$ & $35,0 \%$ & $-724,09$ & $3,4 \%$ & $-21,00$ & $-0,8 \%$ \\
\hline $\begin{array}{l}\text { Quantidade produzida } \\
\text { (Toneladas) }\end{array}$ & 19318,05 & $74,5 \%$ & $-9803,45$ & $474,9 \%$ & $-9651,60$ & $45,4 \%$ & $-137,00$ & $-5,3 \%$ \\
\hline Valor da produção & 3743,42 & $14,4 \%$ & 9205,62 & $-445 \%$ & $-7823,05$ & $36,8 \%$ & 5126,00 & $196,7 \%$ \\
\hline Total & 25942,60 & $100,0 \%$ & $-2064,28$ & $100,0 \%$ & $-21272,60$ & $100,0 \%$ & 2605,72 & $100,0 \%$ \\
\hline $\begin{array}{cc}2005 / 2008 & \text { Brasil/ } \\
\text { Para } & \\
\end{array}$ & $\begin{array}{c}\text { Efeito } \\
\text { Nacional } \\
\end{array}$ & $\%$ & $\begin{array}{c}\text { Efeito } \\
\text { Proporcional } \\
\end{array}$ & $\%$ & $\begin{array}{c}\text { Efeito } \\
\text { Regional } \\
\end{array}$ & $\%$ & $\begin{array}{l}\text { Efeito } \\
\text { total }\end{array}$ & $\%$ \\
\hline $\begin{array}{l}\text { Área destinada à } \\
\text { colheita (Hectares) }\end{array}$ & 1019,42 & $5 \%$ & $-521,04$ & $23 \%$ & $-1314,38$ & $3 \%$ & $-816,00$ & $4 \%$ \\
\hline Área colhida (Hectares) & 1019,42 & $5 \%$ & $-516,66$ & $23 \%$ & $-1318,76$ & $3 \%$ & $-816,00$ & $4 \%$ \\
\hline $\begin{array}{l}\text { Quantidade produzida } \\
\text { (Toneladas) }\end{array}$ & 16659,83 & $77 \%$ & $-8454,47$ & $371 \%$ & $-17780,36$ & $44 \%$ & $-9575,00$ & $46 \%$ \\
\hline Valor da produção & 2932,75 & $14 \%$ & 7212,05 & $-316 \%$ & $-17544,80$ & $44 \%$ & $-7400,00$ & $35 \%$ \\
\hline Total & 21631,42 & $100 \%$ & $-2280,11$ & $100 \%$ & $-40238,42$ & $100 \%$ & $\begin{array}{c}- \\
20887,11 \\
\end{array}$ & $100 \%$ \\
\hline $\begin{array}{c}\text { 2005/2008 Brasil/ } \\
\text { Capitão Poço }\end{array}$ & $\begin{array}{c}\text { Efeito } \\
\text { Nacional } \\
\end{array}$ & $\%$ & $\begin{array}{c}\text { Efeito } \\
\text { Proporcional } \\
\end{array}$ & $\%$ & $\begin{array}{c}\text { Efeito } \\
\text { Regional } \\
\end{array}$ & $\%$ & $\begin{array}{l}\text { Efeito } \\
\text { total } \\
\end{array}$ & $\%$ \\
\hline $\begin{array}{l}\text { Área destinada à } \\
\text { colheita (Hectares) }\end{array}$ & 670,37 & $5 \%$ & $-342,64$ & $17 \%$ & $-327,74$ & $2 \%$ & 0,00 & $0 \%$ \\
\hline Área colhida (Hectares) & 670,37 & $5 \%$ & $-339,76$ & $17 \%$ & $-330,62$ & $2 \%$ & 0,00 & $0 \%$ \\
\hline $\begin{array}{l}\text { Quantidade produzida } \\
\text { (Toneladas) }\end{array}$ & 11396,35 & $78 \%$ & $-5783,38$ & $292 \%$ & $-5612,97$ & $27 \%$ & 0,00 & $0 \%$ \\
\hline Valor da produção & 1823,40 & $13 \%$ & 4484,01 & $-226 \%$ & $-12162,41$ & $60 \%$ & $-5855,00$ & $75 \%$ \\
\hline Total & 14560,50 & $100 \%$ & $-1981,76$ & $100 \%$ & $-20415,50$ & $100 \%$ & $-7836,7$ & $100 \%$ \\
\hline
\end{tabular}

Nos anos de 2008/2011 (Tabela 9) dos pomares possuem baixa podemos perceber uma estagnação no produtividade devido a diversos fatores efeito regional, ou seja, foi um ano que como solos poucos nutridos (OLIVEIRA et não houve investimento e nem perda no al., 2012).

setor a nível regional. A grande maioria 
Tabela 9. Produtividade da região Norte, Pará e Capitão Poço entre 2008-11.

\begin{tabular}{|c|c|c|c|c|c|c|c|c|}
\hline $\begin{array}{c}2008 / 2011 \\
\text { Norte }\end{array}$ & $\begin{array}{c}\text { Efeito } \\
\text { Nacional } \\
\end{array}$ & $\%$ & $\begin{array}{c}\text { Efeito } \\
\text { Proporcional } \\
\end{array}$ & $\%$ & $\begin{array}{c}\text { Efeito } \\
\text { Regional } \\
\end{array}$ & $\%$ & $\begin{array}{l}\text { Efeito } \\
\text { total }\end{array}$ & $\%$ \\
\hline $\begin{array}{l}\text { Área destinada à } \\
\text { colheita (Hectares) }\end{array}$ & 213,47 & $3,8 \%$ & $-210,47$ & $-2,2 \%$ & 0,00 & $0,0 \%$ & 3,00 & $0,0 \%$ \\
\hline $\begin{array}{l}\text { Área colhida } \\
\text { (Hectares) }\end{array}$ & 1955,69 & $34,6 \%$ & $-2358,89$ & $-24,8 \%$ & 334,20 & $0,4 \%$ & $-69,00$ & $-0,1 \%$ \\
\hline $\begin{array}{l}\text { Quantidade } \\
\text { produzida } \\
\text { (Toneladas) }\end{array}$ & 1944,31 & $34,4 \%$ & $-2366,45$ & $-24,8 \%$ & $-861,86$ & $-1,1 \%$ & $-1284,00$ & $-1,4 \%$ \\
\hline Valor da produção & 26362,44 & $466,1 \%$ & $-9334,34$ & $-98,0 \%$ & 3834,89 & $4,9 \%$ & 20863,00 & $22,2 \%$ \\
\hline Total & 5656,25 & $100,0 \%$ & 9528,72 & $100,0 \%$ & 78753,03 & $100,0 \%$ & 93938,00 & $100,0 \%$ \\
\hline $\begin{array}{cc}2008 / 2011 & \text { Brasil/ } \\
\text { Para } & \\
\end{array}$ & $\begin{array}{c}\text { Efeito } \\
\text { Nacional }\end{array}$ & $\%$ & $\begin{array}{c}\text { Efeito } \\
\text { Proporcional }\end{array}$ & $\%$ & $\begin{array}{c}\text { Efeito } \\
\text { Regional }\end{array}$ & $\%$ & $\begin{array}{l}\text { Efeito } \\
\text { total }\end{array}$ & $\%$ \\
\hline $\begin{array}{l}\text { Área destinada à } \\
\text { colheita (Hectares) }\end{array}$ & 213,47 & $7 \%$ & $-210,47$ & $-4 \%$ & 0,00 & $0 \%$ & 3,00 & $0 \%$ \\
\hline $\begin{array}{l}\text { Área colhida } \\
\text { (Hectares) }\end{array}$ & 1305,17 & $41 \%$ & $-1574,26$ & $-29 \%$ & 48,09 & $0 \%$ & $-221,00$ & $-1 \%$ \\
\hline $\begin{array}{l}\text { Quantidade } \\
\text { produzida } \\
\text { (Toneladas) }\end{array}$ & 1305,17 & $41 \%$ & $-1588,54$ & $-29 \%$ & 62,37 & $0 \%$ & $-221,00$ & $-1 \%$ \\
\hline Valor da produção & 21729,54 & $675 \%$ & $-7693,93$ & $-142 \%$ & $-16974,61$ & $-66 \%$ & $-2939,00$ & $-9 \%$ \\
\hline Total & 3217,70 & $100 \%$ & 5420,65 & $100 \%$ & 25781,65 & $100 \%$ & 34420,00 & $100 \%$ \\
\hline $\begin{array}{l}\text { 2008/2011 Brasil/ } \\
\text { Capitão Poço }\end{array}$ & $\begin{array}{l}\text { Efeito } \\
\text { Nacional }\end{array}$ & $\%$ & $\begin{array}{c}\text { Efeito } \\
\text { Proporcional }\end{array}$ & $\%$ & $\begin{array}{c}\text { Efeito } \\
\text { Regional }\end{array}$ & $\%$ & $\begin{array}{l}\text { Efeito } \\
\text { total }\end{array}$ & $\%$ \\
\hline $\begin{array}{l}\text { Área destinada à } \\
\text { colheita (Hectares) }\end{array}$ & 213,47 & $11 \%$ & $-210,47$ & $-7 \%$ & 0,00 & $0 \%$ & 3,00 & $0 \%$ \\
\hline $\begin{array}{l}\text { Área colhida } \\
\text { (Hectares) }\end{array}$ & 915,33 & $49 \%$ & $-1104,05$ & $-35 \%$ & 188,71 & $1 \%$ & 0,00 & $0 \%$ \\
\hline $\begin{array}{l}\text { Quantidade } \\
\text { produzida } \\
\text { (Toneladas) }\end{array}$ & 915,33 & $49 \%$ & $-1114,06$ & $-35 \%$ & 198,73 & $1 \%$ & 0,00 & $0 \%$ \\
\hline Valor da produção & 15560,66 & $833 \%$ & $-5509,67$ & $-175 \%$ & $-10050,99$ & $-47 \%$ & 0,00 & $0 \%$ \\
\hline Total & 1867,24 & $100 \%$ & 3145,62 & $100 \%$ & 21334,15 & $100 \%$ & 26347,00 & $100 \%$ \\
\hline
\end{tabular}

Nos últimos anos analisados 2011/2014 (Tabela 10), o setor volta a crescer principalmente em relação a produtividade tendo em vista que no âmbito nacional os setores sub desenvolviam-se. Esse resultado é evidente, pois nestes anos o Brasil teve uma crescente produção, destacando-se mundialmente. 
Tabela 10. Produtividade da região Norte, Pará e Capitão Poço entre 2011-14.

\begin{tabular}{|c|c|c|c|c|c|c|c|c|}
\hline Brasil/ Norte & $\begin{array}{l}\text { Efeito } \\
\text { Nacional }\end{array}$ & $\%$ & $\begin{array}{c}\text { Efeito } \\
\text { Proporcional } \\
\end{array}$ & $\%$ & $\begin{array}{c}\text { Efeito } \\
\text { Regional }\end{array}$ & $\%$ & $\begin{array}{l}\text { Efeito } \\
\text { total }\end{array}$ & $\%$ \\
\hline $\begin{array}{l}\text { Área destinada à colheita } \\
\text { (Hectares) }\end{array}$ & $-299,49$ & $1,4 \%$ & 302,49 & $-30,7 \%$ & 0,00 & $0,0 \%$ & 2,71 & $0,0 \%$ \\
\hline Área colhida (Hectares) & $-2729,35$ & $12,5 \%$ & $-172,72$ & $17,5 \%$ & 3718,06 & $3,5 \%$ & 816,30 & $1,0 \%$ \\
\hline $\begin{array}{l}\text { Quantidade produzida } \\
\text { (Toneladas) }\end{array}$ & $-2532,47$ & $11,6 \%$ & $-318,52$ & $32,3 \%$ & 3909,99 & $3,7 \%$ & 1059,44 & $1,3 \%$ \\
\hline Valor da produção & $-40036,83$ & $182,7 \%$ & 908,31 & $-92,2 \%$ & 59553,52 & $55,7 \%$ & 20425,91 & $24,3 \%$ \\
\hline Total & $-21913,26$ & $100,0 \%$ & $-985,57$ & $100,0 \%$ & 106988,83 & $100,0 \%$ & 84092,00 & $100,0 \%$ \\
\hline Brasil/ Para & $\begin{array}{l}\text { Efeito } \\
\text { Nacional }\end{array}$ & $\%$ & $\begin{array}{c}\text { Efeito } \\
\text { Proporcional }\end{array}$ & $\%$ & $\begin{array}{c}\text { Efeito } \\
\text { Regional }\end{array}$ & $\%$ & $\begin{array}{l}\text { Efeito } \\
\text { total }\end{array}$ & $\%$ \\
\hline $\begin{array}{l}\text { Área destinada à colheita } \\
\text { (Hectares) }\end{array}$ & $-299,49$ & $3 \%$ & 302,49 & $-70 \%$ & 0,00 & $0 \%$ & 2,33 & $0 \%$ \\
\hline Área colhida (Hectares) & $-1795,44$ & $19 \%$ & $-113,62$ & $26 \%$ & 1692,06 & $3 \%$ & $-216,55$ & $0 \%$ \\
\hline $\begin{array}{l}\text { Quantidade produzida } \\
\text { (Toneladas) }\end{array}$ & $-1795,44$ & $19 \%$ & $-225,82$ & $52 \%$ & 1804,26 & $3 \%$ & $-216,29$ & $0 \%$ \\
\hline Valor da produção & $-30002,12$ & $311 \%$ & 680,65 & $-157 \%$ & 25677,47 & $46 \%$ & $-3642,46$ & $-8 \%$ \\
\hline Total & $-9633,51$ & $100 \%$ & $-433,28$ & $100 \%$ & 56336,78 & $100 \%$ & 46272,00 & $100 \%$ \\
\hline $\begin{array}{l}\text { 2011/2014 Brasil/ } \\
\text { Capitão Poço }\end{array}$ & $\begin{array}{l}\text { Efeito } \\
\text { Nacional }\end{array}$ & $\%$ & $\begin{array}{c}\text { Efeito } \\
\text { Proporcional }\end{array}$ & $\%$ & $\begin{array}{c}\text { Efeito } \\
\text { Regional }\end{array}$ & $\%$ & $\begin{array}{l}\text { Efeito } \\
\text { total }\end{array}$ & $\%$ \\
\hline $\begin{array}{l}\text { Área destinada à colheita } \\
\text { (Hectares) }\end{array}$ & $-299,49$ & $5 \%$ & 302,49 & $-103 \%$ & 0,00 & $0 \%$ & 2,02 & $0 \%$ \\
\hline Área colhida (Hectares) & $-1282,24$ & $20 \%$ & $-81,14$ & $28 \%$ & 1363,39 & $4 \%$ & 0,47 & $0 \%$ \\
\hline $\begin{array}{l}\text { Quantidade produzida } \\
\text { (Toneladas) }\end{array}$ & $-1282,24$ & $20 \%$ & $-161,28$ & $55 \%$ & 1443,52 & $4 \%$ & 0,74 & $0 \%$ \\
\hline Valor da produção & $-21798,14$ & $333 \%$ & 494,53 & $-168 \%$ & 21303,61 & $55 \%$ & 1,65 & $0 \%$ \\
\hline Total & $-6539,44$ & $100 \%$ & $-294,12$ & $100 \%$ & 38704,56 & $100 \%$ & 31873,00 & $100 \%$ \\
\hline
\end{tabular}

Nas figuras a seguir podem serem observados os gráficos que representam as oscilações dos setores avaliados ao longo dos anos, esses valores são reais e não houve comparativo com a taxa nacional nem variações hipotéticas. A Figura 1 é concernente ao gráfico que apresenta os dados a respeito da área destinada à colheita, mostrando que com o tempo o tamanho dessas áreas diminuiu bruscamente. Entre 1990 e 1996, percebese que a quantidade da área de colheita é considerável, de 2002 a 2005, ocorreu uma lenta recuperação, porém, ainda assim, recaiu atingindo um patamar inferior às áreas verificadas em 1990 a 1996. 
Figura 1. Área destinada a colheita (ha) no Brasil, Norte, Pará e Capitão Poço entre 1990 a 2014.

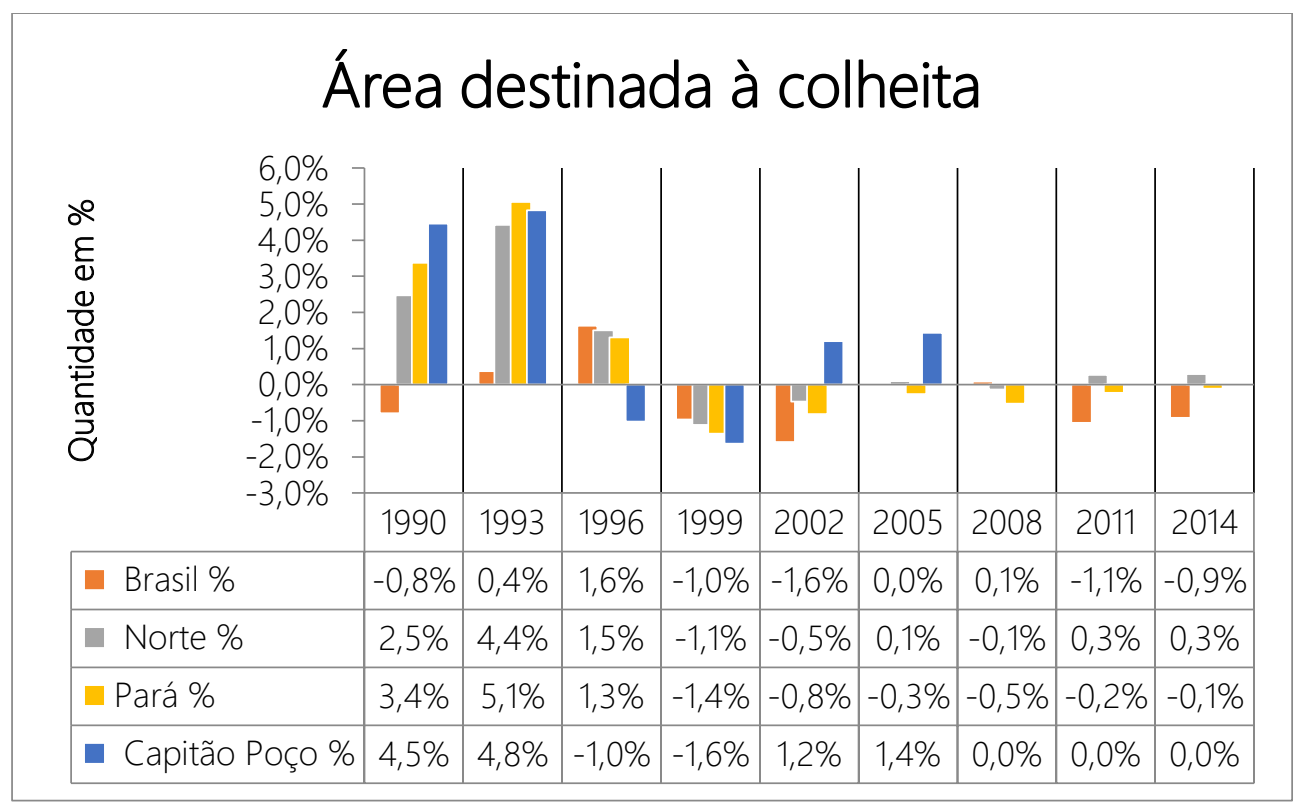

Pode-se observar que a área ocupada pela produção de laranja foi diminuindo e a produção teve uma queda e depois se estagnou isso pode ser associado ao investimento no setor por parte dos agricultores que ao invés de plantar mais procuraram potencializar seus pomares, abrangendo conhecimentos como estudos do clima, solo, genética, portaenxertos, manejos de fitotecnia, nutrientes específicos para a cultura e pragas, afim de evitar problemas futuros. Outro aspecto importante é a valorização da cultura, pois enquanto outros setores só decaiam o valor agregado com a produção só aumentava principalmente na região, estado e município.
Em seu estudo sobre o desenvolvimento da citricultura brasileira Neves et al. (2011), destacou que a citricultura brasileira tem passado por mudanças, tais como alteração do padrão tecnológico, utilização de mudas de melhor qualidade, melhores combinações de porta-enxerto adequados para cada região, melhor manejo dos pomares, qualidade do controle fitossanitário, e dentre as mudanças ocorridas na citricultura, destaca-se a densidade de árvores por hectare.

Fato este que justifica os resultados obtidos para a análise de área destinada a colheita, observados na Figura 1, pode-se observar sua diminuição, já que os produtores passaram a diminuir a 
implantação de novos pomares visando a potencialização da sua produção nas áreas já destinadas a citricultura.

Na Figura 2 verifica-se a grande queda que ocorreu de área colhida, notamos que este dado pode ser considerado diretamente ligado com a diminuição da área destinada à colheita, uma vez que os pomares passaram por mudanças na densidade de árvores por hectare. "Na década de 1990 a densidade de plantio mais utilizada era de 357 árvores/há1, mudando para 476 árvores/há1 no início dos anos 2000 e, atualmente, os pomares mais modernos são formados com 833 árvores/ha" (NEVES et al., 2011). Isto permite a elevada produção mesmo em áreas pequenas.

Figura 2. Área colhida (ha) no Brasil, Norte, Pará e Capitão Poço entre 1990 a 2014.

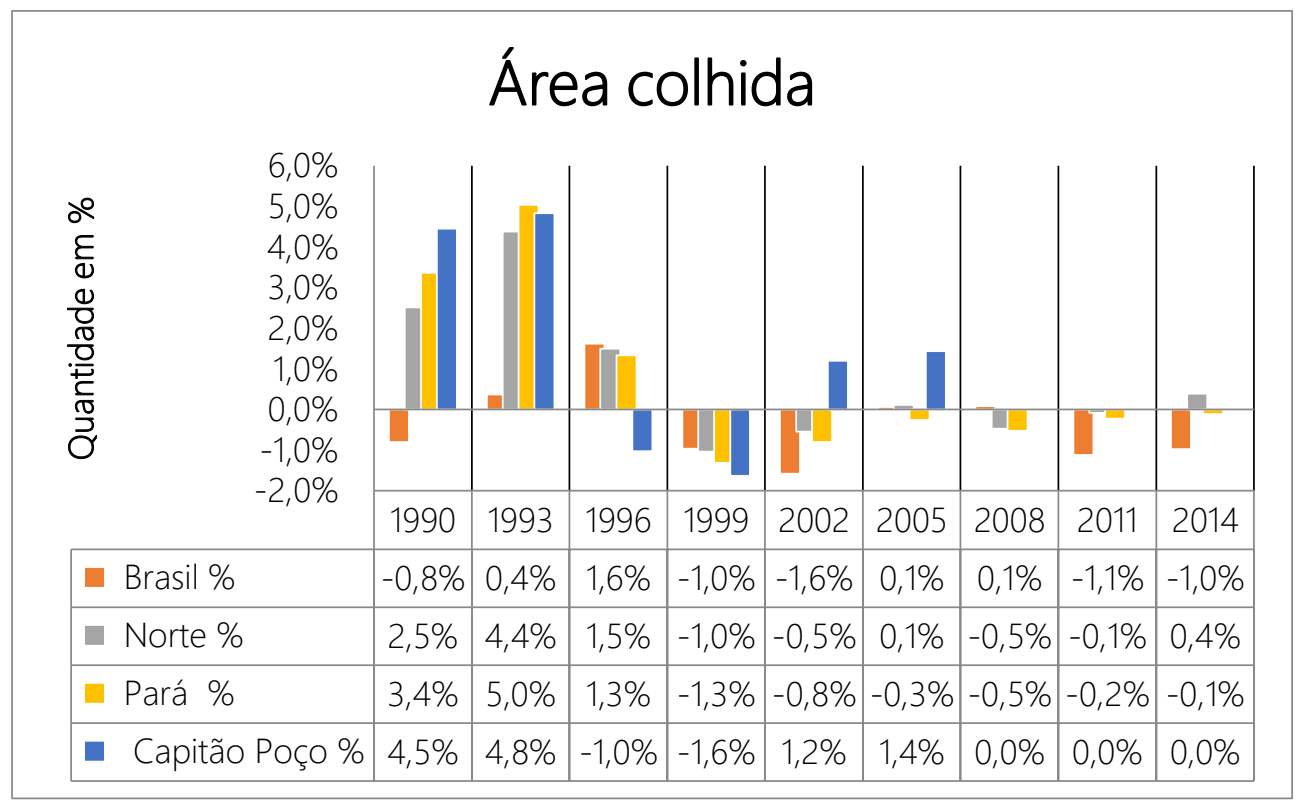

$\mathrm{Na}$ Figura 3 os dados gráficos demonstram a queda na quantidade produzida onde as safras de 1990 e 1993 tiveram destaques significativos, logo após, decaíram subitamente.

Essa queda na produção de acordo com Barros et al. (2016) pode ter sido influenciada pelo movimento no recuo da participação da produção de laranja destinada a fins industriais, esse movimento se deu em meados da década de 90 liderado pelos Estados Unido, Europa, Brasil e outros pequenos produtores. 
A produção do Brasil destinada a indústria passou por grandes reduções, de acordo com dados apresentados pelo autor citado acima a produção do Brasil decresceu 21\% o que representa 64 milhões de caixas a menos que a média das safras 1996/1997 e 1997/1998. Isto pode explicar a queda na quantidade produzida que foi expressada nos dados gráficos.

Figura 3. Quantidade produzida (ton) no Brasil, Norte, Pará e Capitão Poço entre 1990 a 2014.

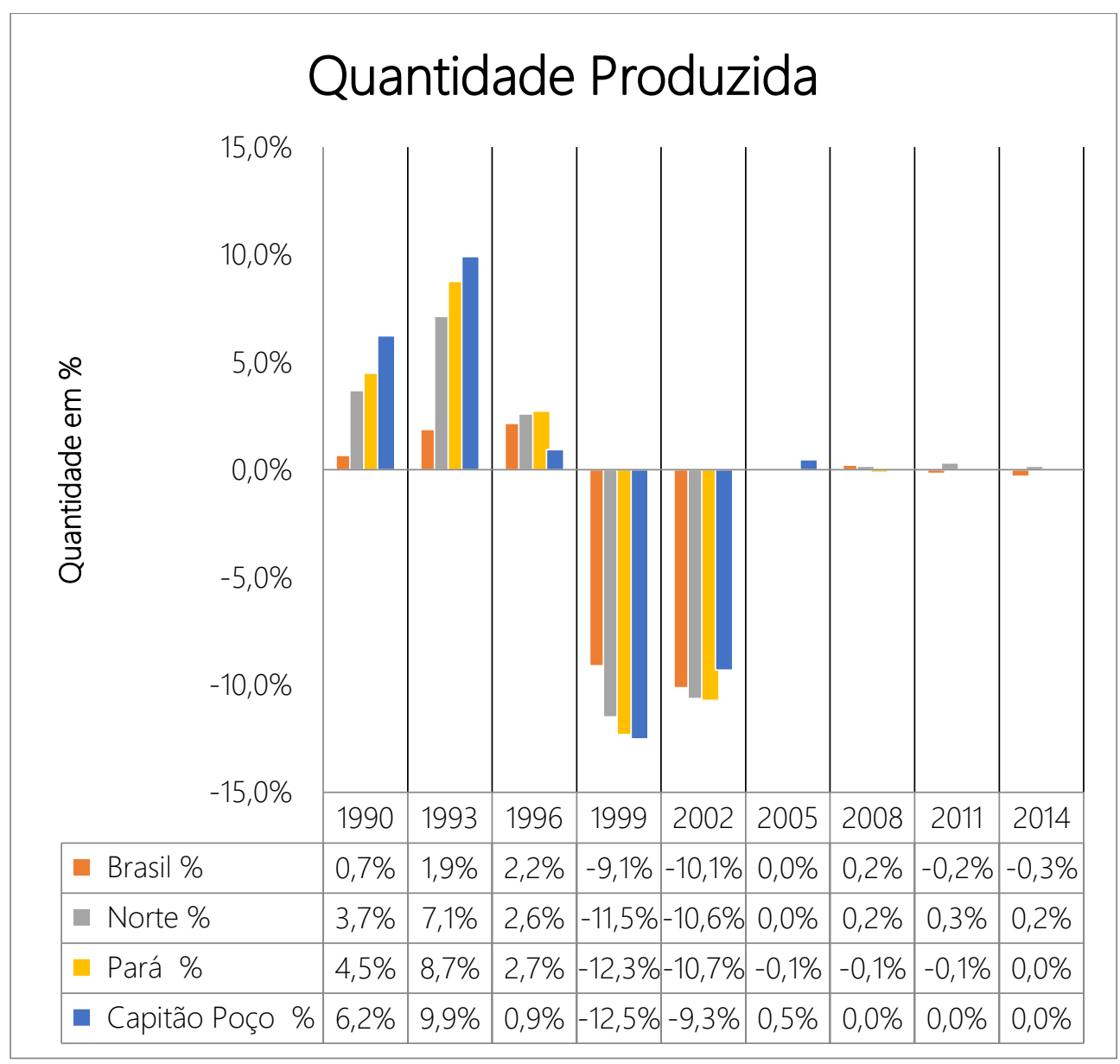

Por fim, pode-se observar na Figura 4 o aumento do valor de produção, que vai na contramão dos demais dados, demonstrando algumas oscilações nos anos iniciais, porém, o valor da produção foi alavancado a partir do ano de 2008. 
Figura 4. Valor da produção (R\$) no Brasil, Norte, Pará e Capitão Poço entre 1990 a 2014.

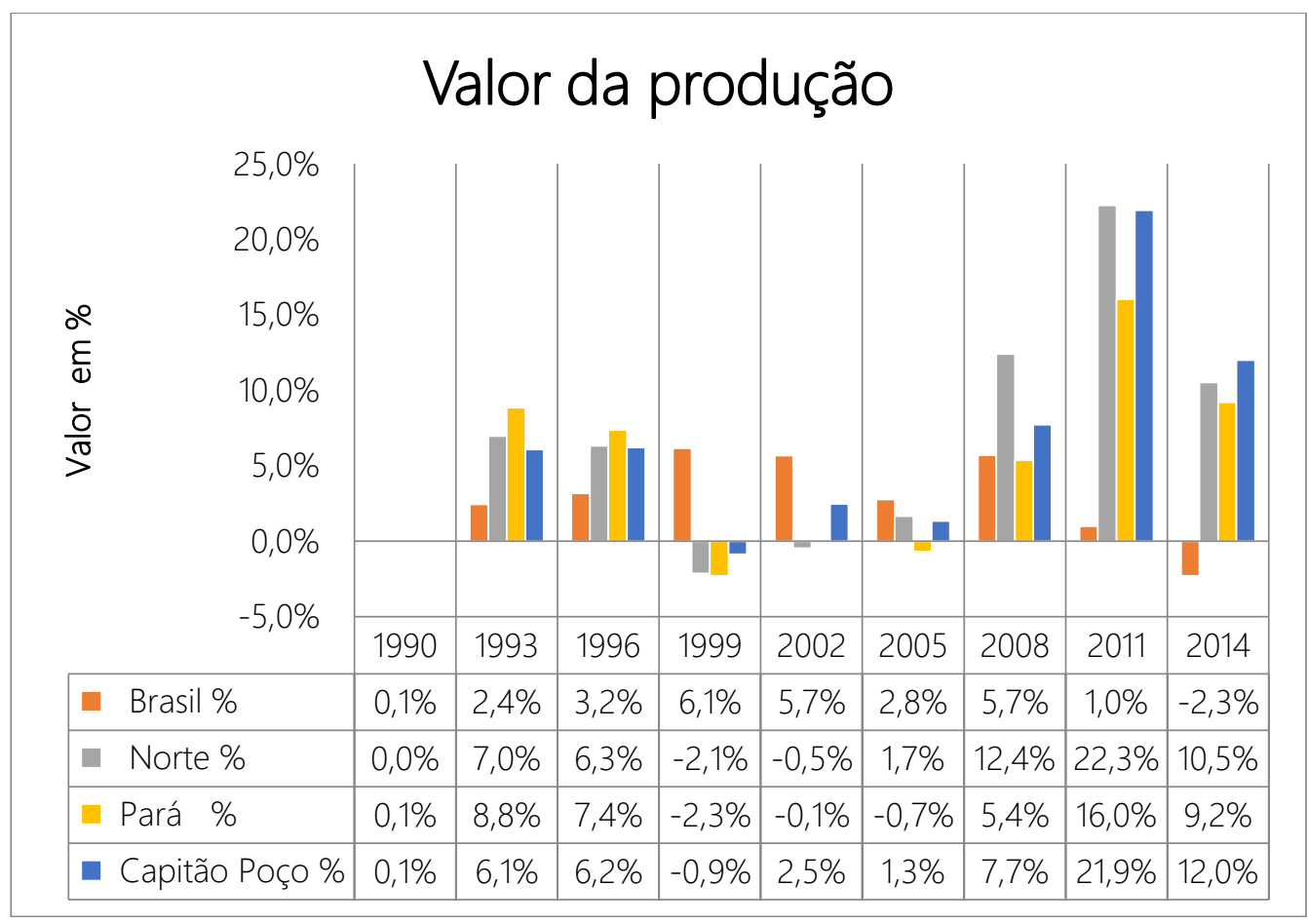

Segundo Neves et al. (2011), a área total destinada a produção de laranja do Brasil diminuiu em cerca de 8\% desde o início da década de 1990. Entretanto, a produção se estabilizou, gerando um ganho em produtividade. A média nacional de 380 caixas do fruto por hectare, em 1990, saltou em 2011 para 475 caixas por hectare. Se a citricultura de hoje não houvesse passado por mudanças tão significativas ao longo dos anos, seriam necessários cerca de 280 mil hectares a mais para atingir a produção atual.

\section{CONCLUSÃO}

Através das análises realizadas podemos inferir diversas coisas a respeito do cultivo de laranja na região Norte, no estado do Pará e no município de Capitão Poço uma delas e a instabilidade principalmente na produção, foi possível notar a independência da produção local em relação a nacional em alguns momentos se tornando até inversamente proporcionais.

Um ponto bastante interessante foi a relação entre produção e área cultivada pois em determinados anos a área 
cultivada aumentava e a produção caia e isso pode está diretamente associado ao baixo nível tecnológico da região e ao baixo investimento na produção juntamente com a baixa fertilidade dos solos paraenses, nos últimos vinte e quatro anos a cultura passou a ser mais valorizada comercialmente assim aumentado o seu valor de mercado como vimos nas análises.

\section{REFERÊNCIAS}

ALMEIDA, L., M., W.; BRITO, D., S.(2005). Atividades de modelagem matemática: que sentido os alunos podem the atribuir?. Ciência \& Educação (Bauru). pp.483-497

ALVES, J. D. N.; MOTA, F. F. A.; FERRAZ, Y. T.; JESUS, R. T. L.; OKUMURA, R. S. (2015). Evolução da Produtividade de Laranja e Pimenta-do-Reino no Período de 2000 a 2012 no Município de Capitão Poço, PA. Enciclopédia Biosfera, Centro Científico Conhecer - Goiânia, v11, n. 21, p.10681077, 2015.

AMARO, A. A.; MAIA, M. L. Produção e comércio de laranja e de suco no Brasil. Informações Econômicas, SP, v.27, n.7, jul. 1997.

BARROS, J. R. M.; BARROS, A. L. M.; CYPRIANO, M. P. (2016). O mercado da citricultura no Brasil e as suas novas perspectivas. Disponível em: $<\underline{\text { http://www.citrusbr.com/download/bibli }}$
oteca/CitrusBR Livro Concecitrus 2016.p d). Acesso em: 26 de ago. 2017.

DUNN, E. S. J. A. Statistical and Analytical Techniques for Regional Analysis. Papers Regional Science Association. n. 6, 1960.

EMBRAPA. (2013). TABELA - Produção brasileira de laranja em 2013. Disponível em:<https://www.embrapa.br/documents /1355135/1529009/Laranja_Brasil_2013.pdf /5c85ffa4-f792-4db8-b1e7-

2940d1cf07e5 >. Acessado em: 25 ago. de 2017.

FIGUEIREDO, P. P. Condições higiênicosanitárias no preparo de suco de laranja in natura em lanchonetes comerciais em Goiânia, GO. Revista Ciência e Saúde, São Paulo, v. 27, n. 4, p. 574-375, 2009.

MANTAl, R., D.; TIECKER, M. M. (2011). Utilização de derivadas parciais em levantamentos topográficos. Ensino de Ciências e Tecnologia em Revista. vol. 1, n. 1. jan./jun. 2011.

NEVES, M. F.; TROMBIN, V. G.; MILAN, P.; LOPE, F. F.; KALAK, R. O retrato da citricultura brasileira. FEA/USP. Ribeirão Preto- SP, 2011. Disponível em: <http://www.citrusbr.com/download/bibli oteca/Apresentacao_Marcos_Fava_event o_valor.pdf> . Acesso em: 12 nov. 2017.

OLIVEIRA, I., P.; OLVEIRA, L. C.; MOURA, C. S. F. T.; Alguns fatores bióticos e abióticos que afetam a qualidade de laranja no mercado. Revista Faculdade Montes Belos, v. 5, n. 4. 113-136 p. ago 2012.

OLIVEIRA, J. C.; PERDIGÃO, P. S.; SIQUEIA, K, A. G.; SANTOS, A. C.; MIGUEL, M. A. L. Características microbiológicas do suco 
de laranja in natura. Ciências e Tecnologia de alimentos, vol.26 n.2, Campinas Abril/June, 2006.

PEREZ, O. C; SANTOS; V. H. A. (2014). Exportação de suco de laranja Brasileiro. Revista de administração da fatea, v. $9, n^{\circ}$. 9, p. 101-109.

RIBEIRO, S. I.; E. G. da; RIBEIRO, N. S. V. (2006). Desempenho de laranjeiras em Capitão Poço, PA. Belém, PA: Embrapa Amazônia Oriental. 16 p. il (Embrapa Amazônia Oriental. Boletim de pesquisas e desenvolvimento, 57). Versão eletrônica. $1^{a}$ impressão: 2009. Disponível em: $<$ https://www.embrapa.br/busca-depublicacoes//publicacao/889558/desempenho-delaranjeiras-em-capitao-poco-pa>. Acesso em: 12 de nov. de 2017.

SILVA, A.G.; BOIÇA JUNIOR, A.L.; FARIAS, P.R.S. Influência da temperatura e precipitação na infestação de moscanegra-dos-citros (Aleurocanthus woglumi) em plantio de citros. Revista Nucleus, Ituterava, v.8, n.1, p.53-60, 2011.

ZILLI, J. B.; CANDATEN, J.; NUNES, L. Efeitos das alterações no preço e na produtividade da produção de leite no Rio Grande do Sul. Teoria e Evidência Econômica v. 21, n. 45, 332-352 p 